\title{
1966-2016: Cinco Décadas de DADOS - Revista de Ciências Sociais
}

\section{Breno Bringel}

Editor, DADOS - Revista de Ciências Sociais

Universidade do Estado do Rio de Janeiro (UERJ), Rio de Janeiro, RJ, Brasil. E-mail: brenobringel@iesp.uerj.br

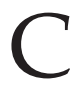
elebramos em 2016, com enorme alegria, um momento duplamente simbólico para a DADOS - Revista de Ciências Sociais: por um lado, completávamos com o primeiro número do ano (vol. 59) cento e cinquenta números publicados; por outro, a revista cumpria cinquenta anos de existência. Durante estas cinco décadas foram publicados 947 artigos, excluindo-se desta somatória dezenas de notas de pesquisa, cronologias, bibliografias comentadas e resenhas publicadas desde o primeiro número em 1966 até o trigésimo quinto, correspondente ao volume 27 (no 1) de 1984, quando a revista passou a publicar exclusivamente artigos. Estes quase mil textos incluem contribuições de vários dos principais intelectuais do Brasil e do exterior e textos seminais da ciência política, da sociologia e da antropologia nacional, que auxiliaram a demarcar e a consolidar subáreas, e a estimular novos debates.

O aniversário é motivo de muito orgulho, pois se trata, infelizmente, de fato raro em nosso país e em nossa região, onde as publicações científicas não se caracterizam precisamente por sua longevidade. No final de 1966, quando DADOS foi fundada, a Unesco concluiu uma pesquisa sobre os periódicos em ciências sociais em oito países no mundo, incluindo o Brasil. Os resultados foram publicados em 1967 no International Social Science Journal (vol. XIX, no 2). Foram identificados no caso

DADOS - Revista de Ciências Sociais, Rio de Janeiro, vol. 60, n3, 2017, pp. 589 a 601. 
brasileiro quarenta e um periódicos em circulação naquele momento, boa parte dos quais vinculados a instituições que já não mais existem. Além de DADOS, somente quatro deles seguem em circulação: os Anais da Academia Brasileira de Ciências, a Revista Brasileira de Economia, a Revista Brasileira de Política Internacional e a Revista de Administração Pública ${ }^{1}$.

Carlos Alberto de Medina foi o responsável de sistematizar os resultados da pesquisa sobre o caso brasileiro em artigo publicado em 1967 em português em outra bela, porém defunta, revista: América Latina, editada no Rio de Janeiro pelo Centro Latino-americano de Pesquisas em Ciências Sociais (CLAPCS) entre 1962 e 1976. Medina foi enfático: "publicar um periódico no Brasil é um ato heroico" ${ }^{2}$. Embora o panorama hoje não seja exatamente o mesmo, alguns problemas permanecem desde então (principalmente a escassez de financiamento e a precariedade e insuficiência de pessoal especializado), fazendo com que a assertiva de Medina seja profundamente atual.

Tendo em vista os desafios atuais para a editoração científica, a trajetória da DADOS, para além de um caso específico, pode contribuir também para um exame mais geral das persistentes dificuldades na editoração de periódicos em ciências sociais no Brasil, bem como para o enfrentamento de agendas emergentes. Isso implica olhar para trás, sempre com uma mirada aberta e prospectiva. Aprender com os erros e os acertos. Diferenciar os elementos conjunturais das dimensões mais estruturais da publicação de periódicos e da circulação de conhecimento. Ao longo de seus cinquenta anos DADOS transitou por três momentos principais e estamos imersos no início de uma quarta fase. Discuto a seguir alguns dos marcos mais significativos desta trajetória como forma de construir uma apresentação geral ao Dossiê Dados - 50 anos, que conta com um a série de artigos que permitem uma análise mais substantiva da contribuição da revista ${ }^{3}$.

\section{OS INÍCIOS}

Uma primeira etapa, que compreende as décadas de 1960 e 1970, correspondeu à criação e institucionalização da revista. DADOS nasce em 1966 em um momento extremamente turbulento da vida política brasileira após o golpe, consciente de que o cientista social não poderia ser um mero espectador da crise. A disputa pelos sentidos da mudança social e de uma visão abrangente do desenvolvimento e da sociedade era 
um imperativo do momento e marca característica da publicação. A nota editorial do primeiro número da revista é explícita:

a presente revista rejeita uma visão rarefeita da ciência social e procura, ao eco daquele veio profundo do pensamento brasileiro, retomar o compromisso com a totalidade (...). Intento esse que acima de tudo reclama um profundo diálogo com as correntes do pensamento social do país, na medida em que é de uma tensão polêmica que se pode, por sobre a confrontação de escolas, ensaiar a verdadeira articulação de gerações no processo social brasileiro (noㅡ 1, 2o semestre de 1966).

Reivindica-se, para tal fim, o legado dos Cadernos do Nosso Tempo, findado uma década antes do surgimento de DADOS, embora com uma clara guinada rumo a um esforço de maior rigor científico, afim às técnicas e recursos emergentes com o avanço das ciências sociais naquele momento.

A pretensão inicial era a publicação de números semestrais. Contudo, as dificuldades em manter uma publicação que pensava com autonomia a política e a sociedade em plena ditadura militar, além de restrições de ordem prática, não permitiram exatamente isso. A periodicidade acabou sendo pendular nesta primeira etapa, com dificuldades para publicar em alguns anos (1974 e 1975) e variações entre números anuais e semestrais (casos de 1968 e 1973), até chegar em 1977 a uma periodicidade quadrimestral, que duraria exatamente vinte anos. Chama a atenção neste primeiro momento a diversidade de formatos de publicação, o grau de integração dos debates intelectuais em chave nacional e regional, bem como as tentativas de delimitação disciplinar e temática dos debates nas contribuições dos autores brasileiros.

A publicação de notas de pesquisa, bibliografias comentadas, cronologias, resenhas, comentários críticos de livros nacionais e internacionais e de notícias relevantes do antigo Instituto Universitário de Pesquisas do Rio de Janeiro (Iuperj) e das ciências sociais são marcas da tentativa constante de mapeamento, sistematização, diálogo crítico com a produção científica internacional e geração de novos cânones interpretativos. Decerto, o diálogo sistemático entre os autores e os debates internacionais provinham inicialmente de dois lugares principais: por um lado, os Estados Unidos, país com o qual os professores do antigo Iuperj (atual Instituto de Estudos Sociais e Políticos da Universidade do Estado do Rio de Janeiro, IESP-UERJ) possuíam uma intensa interação em termos acadêmicos, motivada sobretudo pela realização de 
suas teses de doutoramento em universidades daquele país; por outro, a América Latina, que possuía um circuito regional sólido de redes intelectuais e agendas de pesquisa, as quais DADOS contribuiu para consolidar e difundir. Neste último caso, o exílio contribuiu a fortalecer estas interações, em razão da presença de intelectuais de outras partes da região no país e vice-versa ${ }^{4}$.

A partir de 1970 ensaiou-se uma breve experiência de publicar, para além dos artigos ordinários, textos aglutinados ao redor de temáticas concretas, baseados em uma seleção de editores convidados. Estes "dossiês temáticos" incluíram os seguintes temas: "Sociedade e Estado" (editado por Simon Schwartzman, 1970), "Análise Política" (editado por Peter McDonough, 1971), "Desempenho do Sistema Político" (editado por Wanderley Guilherme dos Santos, 1972), "Distribuição de Renda no Brasil" (editado por Tito Ryff, 1973). Tanto estes números temáticos como os artigos em geral estiveram sempre marcados por uma forte vocação interdisciplinar, tendo a sociologia e a ciência política como áreas centrais, abrindo-se para um diálogo estreito nesta primeira etapa da revista sobretudo com a antropologia, a economia e a história.

Não seria exagerado dizer que nesta primeira fase, de forma análoga à trajetória do antigo Iuperj, DADOS desempenhou um papel central na agregação do debate intelectual e das publicações de ciências sociais no país, tanto pelo conteúdo da revista em si, como por sua constante preocupação em incentivar a cooperação e o avanço da produção científica brasileira. Uma das mostras mais claras disso foi que após a fundação, em setembro de 1977, da Associação Nacional de Pós-Graduação e Pesquisa em Ciências Sociais (Anpocs) em nossa sede da Rua da Matriz, 82, DADOS se responsabilizou, através de um acordo com o Grupo de Documentação em Ciências Sociais, pela edição do Boletim Informativo e Bibliográfico de Ciências Sociais, mais conhecido como BIB.

O objetivo do $B I B$ era contribuir com o desenvolvimento institucional das ciências sociais no Brasil, facilitando o contato entre as instituições e centros de pesquisa, bem como estimulando o intercâmbio entre cientistas sociais do país. A publicização de notícias, pesquisas, eventos, dissertações de mestrado e de teses de doutorado e resenhas que existiam na primeira década de DADOS foram deslocadas para o $B I B$, ganhando também maior escopo e dimensão nacional, além de incluir, em seus primeiros números, descrições detalhadas dos perfis de insti- 
tuições e centros de ciências sociais. Vale ressaltar que, para além deste elo fundacional, em seus primeiros anos o BIB era publicado como um suplementado da DADOS, autonomizando-se em meados dos 1980.

A chegada de Charles Pessanha à editoria da revista em 1976 foi decisiva. Após uma primeira década na qual os números iniciais de DADOS foram editados por seis editores diferentes (por ordem cronológica, Cesar Guimarães, Bolívar Lamounier, Amaury de Souza, Wanderley Guilherme dos Santos, Olga Lopes da Cruz e Simon Schwartzman ${ }^{5}$, Charles foi progressivamente profissionalizando a revista, a partir de uma aposta explícita em que a divulgação de trabalhos de interesse social e político, com capacidade de interpelação e intervenção nos debates públicos, não é incompatível com a qualidade acadêmica e com o rigor científico. Esta, aliás, é uma marca fundadora da revista que segue vigente.

\section{PROFISSIONALIZAÇÃO}

Publicada a partir do ano de 1980 com um novo desenho gráfico, mais moderno, DADOS realiza uma parceria com a Editora Campus, assegurando facilidades para a impressão e a comercialização. Se antes todos os números eram contados de maneira corrida e continham apenas um volume, a partir deste momento, os volumes passam a conter três números anuais.

As mudanças, no entanto, não foram somente formais e estéticas. A década de 1980 inaugura-se para a revista com uma guinada profissional inovadora e inédita no panorama das revistas científicas brasileiras. Além disso, como bem lembra a nota editorial do vol.23, no1 (1980), este novo momento de DADOS coincide com o início do programa de Doutorado em Ciência Política e Sociologia do antigo Iuperj em março de 1980, cujo legado persiste hoje nos Programas de Pós-Graduação em Sociologia e em Ciência Política do atual IESP-UERJ ${ }^{6}$.

Destarte, dentre as mudanças efetivadas, pode-se enfatizar as seguintes novidades: a) a adoção de um padrão profissional de produção gráfica e comercialização; b) a parceria com editores-associados que passaram a auxiliar o(s) editor(es) (foram eles: Alexandre de S. C. Barros, Carlos Hasenbalg, Cesar Guimarães, Elisa Reis, Luiz Antonio Machado da Silva, Luiz Eduardo Soares e Renato Boschi); c) a ampliação do conselho editorial com membros internos do Instituto e a construção de um conselho consultivo nacional com membros externos de 
renome na academia brasileira; d) a busca de artigos mais concisos; e) a indexação nos principais índices internacionais, incluindo o Institute for Scientific Information - ISI - da Thomson Co.; f) a adoção de pareceres - inicialmente abertos e posteriormente em formato duplo cego - e a publicização (feita desde 1986) no último número da revista dos nomes dos pareceristas que colaboraram com avaliações para a qualidade da publicação.

A execução deste padrão profissional somente foi possível pela presença de uma redação ativa e de profissionais que, na contramão da tendência nacional, foram se aperfeiçoando e se especializando na editoria científica em ciências humanas. O trabalho cuidadoso do texto, do estilo, da revisão ortográfica e de todas as etapas de produção dos artigos publicados marcaram a qualidade do projeto editorial da revista desde então. Entre as secretárias que deixaram marcas importantes na revista pelo seu tempo e dedicação estão Beth Cobra, Elisabeth Lissovsky, Patrícia Campos de Sousa, Sabrina Primo, Tema Pechman e Claudia Boccia, memória viva da DADOS e amiga comprometida desde a década de 1990 até hoje com o projeto editorial da revista.

A existência de uma equipe de profissionais de competência ímpar nas ciências sociais no Brasil permitiu que, uma vez mais, na redação de DADOS fossem criadas iniciativas que beneficiavam toda a comunidade acadêmica. Por um lado, pode-se destacar, por exemplo, a criação de uma importante base de dados on-line, o Data Índice. Por outro, a criação em 1985, com participação ativa de Charles Pessanha, da Associação Brasileira de Editores Científicos (ABEC), com o objetivo de aprimorar a publicação de periódicos científicos e aperfeiçoar a comunicação e divulgação de informações.

O contexto era de profissionalização não somente para a DADOS, mas também para as ciências sociais. Em apresentação ao número do vigésimo aniversário da revista, Cesar Guimarães, então diretor-executivo do Instituto, assevera: "nestes vinte anos, a Ciência Social respondeu ao repto da realização adversa crescendo e se institucionalizando. DADOS é um de seus testemunhos, em conteúdo e forma" (vol.29, no3, 1986). De fato, se o contexto político dos primeiros vinte anos da revista era adverso, abria-se desde então um novo momento de crescimento das ciências sociais. O teor dos artigos publicados é prova disso. Debates mais especializados convivem com textos seminais do debate inte- 
lectual e público sobre ação coletiva, transição à democracia e presidencialismo de coalizão, entre outros temas.

A redemocratização e a entrada na década de 1990 levam à proliferação de uma agenda sempre pluralista de artigos que, sem abandonar o diálogo disciplinar, vai progressivamente delimitando-se de maneira mais estrita na ciência política e na sociologia ou em suas fronteiras, na sociologia política: atores e movimentos sociais, democracia, Estado, políticas públicas, eleições, partidos, comportamento coletivo são temas que vão ganhando mais peso juntamente com temas clássicos da revista associados à estrutura social, aos estudos urbanos, ao pensamento social e político ou à teoria social e política. Neste momento, a revista adquire em 1990 o seu layout atual e passa a ser produzida e distribuída pela editora Vértice.

\section{CONSOLIDAÇÃO E OS DESAFIOS DA ERA DIGITAL}

DADOS cumpria em 1996 três décadas dispondo de um dos mais importantes acervos bibliográficos dentre as revistas brasileiras da sua grande área de atuação. Este novo aniversário coincide com a concepção da SciELO - Science Electronic Library Online e com o desenvolvimento, um ano mais tarde, de seu projeto piloto, que incluía inicialmente uma seleção de dez revistas brasileiras, entre elas a DADOS, o primeiro periódico de ciências humanas a fazer parte do projeto.

A criação definitiva da SciELO em 1998 supôs uma transformação profunda na rotina do periódico, influenciando desde a produção dos manuscritos (que deixava para trás o trabalho das digitadoras e o recebimento dos originais por cartas) ao modelo de comunicação (até então baseado em um papel proativo do periódico em preservar a memória e divulgar da forma mais ampla possível os números à comunidade acadêmica e à sociedade como um todo).

Em um momento no qual a internet ainda não se havia massificado, a publicação em formato on-line permitia buscar uma forma complementar (inicialmente não alternativa ou substitutiva) ao papel em termos de difusão do conhecimento. Paulatinamente, como é sabido, o formato digital foi ganhando maior protagonismo, deslocando hoje a centralidade do formato impresso. Contudo, embora todos os números de DADOS possam ser consultados em acesso aberto no SciELO desde 1996, a revista seguiu tendo uma tiragem em papel, cujo destino 
principal são as prateleiras de assinantes (indivíduos e instituições) e as bibliotecas do Brasil e do exterior.

Para além dos efeitos coletivos sobre a divulgação, a qualidade, a integração e a visibilidade dos periódicos nacionais, a entrada de DADOS no SciELO também repercutiu em termos de aprofundamento da profissionalização já iniciada anteriormente, com ênfase para a maior transparência no processo de tramitação dos artigos.

Em termos contextuais, esta nova "era digital" coincidiu com um momento de transformação das universidades brasileiras, de expansão das pós-graduações e de uma maior especialização dos debates das ciências sociais e humanas. O número de periódicos também aumentou vertiginosamente, nem sempre acompanhado de qualidade. As avaliações das pós-graduações nacionais e dos periódicos passam a se integrar de maneira profunda, gerando cenários de grande pressão em autores e editores, pois a publicação converte-se muitas vezes em um fim em si mesmo e não em um meio para a divulgação de resultados de pesquisa e para o diálogo que estimula o avanço da ciência.

Neste novo cenário, mais plural, complexo e heterogêneo, há diversos atores, visões e perspectivas em disputa ${ }^{7}$. Por um lado, tendo em vista o fortalecimento de uma lógica mercantil agressiva de grandes grupos econômicos que criaram um verdadeiro oligopólio de revistas científicas com epicentro no mundo anglo-saxão, abre-se uma ameaça concreta para o acesso aberto e práticas alternativas e autônomas de editoração. Por outro, o maior volume de periódicos provocou um aumento progressivo e exponencial do número de artigos recebidos. Respondendo à ascensão da demanda, DADOS passa a publicar desde 1998 quatro números ao ano e vem constantemente aumentando o número de artigos publicados e pensando fórmulas de atualização diante das reconfigurações do mundo editorial, da divulgação científica e do papel dos periódicos especializados.

Para além destes elementos externos, a transição institucional em meados de 2010, após longa crise da entidade mantenedora, dos docentes e discentes do antigo Iuperj para o IESP-UERJ trouxe um cenário delicado para a revista. Na história recente brasileira sabemos que o fim das revistas muitas vezes está associado ao fim e/ou à crise das instituições que a editam. A solução inovadora de transição institucional para o IESP-UERJ permitiu que, a despeito das turbulências inerentes a um processo com estas características, o mesmo corpo de docentes e de 
funcionários que sempre mantiveram a DADOS, permanecessem editando a revista, mesmo que com muitos sacrifícios. Esta, aliás, talvez tenha sido uma das maiores fortalezas da trajetória da revista, que somente obteve e manteve sua qualidade, projeção, profissionalização, pontualidade e reconhecimento entre os pares devido a uma ampla colaboração de toda a comunidade acadêmica e ao empenho de décadas de sólida ação coletiva de seus editores e do apoio decisivo dos colegas do IESP-UERJ. Isso inclui o cuidado de todos os passos de editoração da revista e de sua gestão cotidiana, inclusive a busca de financiamento (obtido inicialmente junto à Fundação Ford e Finep, em seguida junto ao CNPq e à CAPES e, mais recentemente, sem excluir os três últimos, junto à Faperj).

\section{O MOMENTO ATUAL}

Em nota editorial do primeiro número de 2013, quando assumi a editoria de DADOS, anunciava a necessidade de um projeto de renovação da revista, que incluía tanto medidas e debates estratégicos quanto iniciativas mais técnicas de gestão e editoração dos artigos recebidos, de tal forma que pudéssemos melhorar a pontualidade e a transparência no processamento dos textos. Desde então, buscamos aliar a renovação e a inovação com a tradição e o acúmulo de experiências da revista. Para tal fim, o diálogo geracional tem se mostrado decisivo, seja na editoria com Charles Pessanha, seja no conselho de redação, que se reúne mensalmente para deliberar sobre os novos artigos recebidos e sobre as decisões mais importantes da revista.

Novas instruções aos autores e formatos de divulgação on-line foram inseridas em 2013, quando o espanhol passou a ser idioma oficial da revista, além do português. A maior visibilidade da revista fora do Brasil, bem como a manutenção e a ampliação da presença de DADOS em indexadores internacionais fez com que o volume de artigos provenientes do exterior aumentasse de forma exponencial. O número total de artigos recebidos ampliou-se de forma abrupta, tal como apontado por Charles Pessanha em sua bela introdução à coleção, disponível neste dossiê.

Este cenário tornou inviável a manutenção de um sistema manual de submissões e de processamento de artigos e exigiu novas reconfigurações internas em 2015. Por um lado, revisamos profundamente a política editorial e as normas editoriais e de apresentação dos artigos. Intro- 
duzimos um processo de avaliação bastante mais rigoroso, composto por um triplo filtro de avaliação: o primeiro filtro, realizado pelo Editor-chefe com o apoio da Assistente de Redação, é de caráter estritamente formal e avalia se o texto segue as normas editoriais e de apresentação (vide abaixo). O segundo, realizado pelo Conselho de Redação, com apoio do Conselho Editorial, decide se o artigo se adequa ou não ao escopo de DADOS. Em caso negativo, elabora uma carta explicando os motivos da rejeição. Em caso positivo, indica nomes de avaliadores ad hoc, sempre doutores e com reconhecida expertise no tema. Finalmente, o terceiro filtro é feito pelo Conselho Consultivo que, a partir de avaliações sempre anônimas (para autores e pareceristas), auxilia o Editor-chefe na tomada da decisão final, comunicada mediante uma carta decisória. Mais da metade dos artigos não passa do segundo filtro, seja por problemas formais seja pela incompatibilidade com o escopo da revista, que somente aceita artigos inéditos que contribuam para a inovação teórica, metodológica e/ou análise empírica.

Por outro lado, passamos a adotar em abril de 2015 a plataforma Scholar One Manuscripts. Isso significa que os artigos somente podem ser submetidos de forma eletrônica, permitindo à editoria da revista um melhor controle do recebimento e processamento dos artigos, além de uma maior transparência do processo de avaliação. A nova plataforma possibilita também reconstituir de forma mais precisa os indicadores de desempenho do processo de avaliação dos artigos submetidos, contribuindo à democratização da gestão editorial. Embora somente tenhamos os dados brutos para anos anteriores, passamos a fazer um monitoramento minucioso desde a entrada na plataforma Scholar One. Publicaremos uma nota editorial no primeiro número de 2018 de DADOS com as informações detalhadas sobre os artigos recebidos entre 2015 e 2017.

Somam-se a estas medidas, outras novidades para o biênio 2017-2018: a) a criação de uma página web própria de referência, vinculada à atual página da revista na plataforma SciELO; b) a adesão às redes sociais $\mathrm{Fa}$ cebook, Twitter e Academia; c) a construção de novos formatos digitais de permuta e intercâmbio com periódicos nacionais e internacionais; d) a realização de uma nova campanha de doação de exemplares impressos da revista; e) a publicação, em breve, de artigos no formato de publicação contínua; f) a publicação, dependendo do teor do artigo e da decisão do conselho de redação, simultânea de artigos em português e em inglês. 
Com estas iniciativas, espera-se adotar novos elementos que permitam manter a tradição do periódico com uma aposta explícita de renovação, com impactos positivos nos aspectos técnicos de gestão e editoração dos artigos, na pontualidade e na profissionalização, na internacionalização, na divulgação e no uso das novas tecnologias de informação e comunicação.

Pretende-se que o momento simbólico possa servir para fazer um balanço amplo sobre as últimas cinco décadas das ciências sociais e humanas no Brasil, principalmente a ciência política e a sociologia, a partir da análise da trajetória da DADOS. Este é, em última instância, o objetivo dos artigos de Luiz Augusto Campos, João Feres Júnior e Fernando Guarnieri e Christian Edward Cyril Lynch que acompanham este dossiê.

No entanto, os artigos publicados no presente número buscam transcender a própria revista, adentrando-se no debate sobre as revistas de ciências sociais no país e na América Latina e sobre a construção histórica e a configuração da sociologia e da ciência política. Isso pressupõe: a) a reconstrução da experiência editorial e intelectual da revista vis-à-vis a transformação, ao longo do tempo, dos contextos políticos e institucionais; b) a análise teórico-metodológica, que inclui os principais artigos, aportes e o exame da evolução das áreas e subáreas temáticas, bem como dos principais conceitos e métodos; e, finalmente, c) a discussão sobre os cenários, atores e políticas contemporâneas que orientam as ciências sociais e humanas no Brasil e no mundo e, em particular, os periódicos científicos.

Cinquenta anos depois da criação de DADOS, o contexto político e científico é consideravelmente distinto ao de 1966. Bastante se avançou no sentido da democratização sociopolítica e da institucionalização e profissionalização dos periódicos científicos. As universidades, embora de maneira insuficiente, também se expandiram e democratizaram seu acesso. No entanto, as tentativas de desestabilização e o cenário de polarização atual levam a um sério risco de retrocessos, com sequelas já visíveis das sequências da "crise" fluminense e nacional, que assola fortemente a Universidade do Estado do Rio de Janeiro (UERJ). Por outro lado, muitos periódicos acabaram caindo em um ultra-academicismo, fechando-se em circuitos totalmente endógenos e altamente especializados. Navegando contra estas duas correntes, DADOS não se furtará ao debate público qualificado, parte de seu 
DNA, conciliando o rigor científico e teórico-metodológico com a ênfase em questões substantivas da sociedade e da política.

Longa vida à UERJ, ameaçada pela irresponsável política do governo atual do estado do Rio de Janeiro, e à DADOS, um patrimônio das Ciências Sociais brasileiras. 


\section{NOTAS}

1. A pesquisa da Unesco cobriu revistas especializadas em economia, antropologia, direito, administração, política e história, bem como periódicos de ciências sociais em geral e outros, mais abrangentes ou de temas específicos, que tinham abertura para as ciências sociais. Este é o caso dos Anais da Academia Brasileira de Ciências, publicado de forma ininterrupta desde 1929. Já a Revista Brasileira de Política Internacional nasce em 1958. Finalmente, a Revista de Administração Pública, editada pela Fundação Getulio Vargas, nasce em um sentido estrito em 1967, embora seja uma continuidade do Boletim do Centro de Pesquisas Administrativas da EBAP, criado em 1964.

2. MEDINA, Carlos Alberto de (1967), "Estudo sobre Periódicos de Ciências Sociais no Brasil", América Latina (CLAPCS), Rio de Janeiro, ano 10, no 2, p. 32.

3. Os artigos de Charles Pessanha, Luiz Augusto Campos, João Feres Júnior e Fernando Guarnieri, Christian Edward Cyril Lynch foram apresentados inicialmente no dia 25 de novembro de 2016 em um seminário comemorativo celebrado no IESP-UERJ, do qual também participaram como expositores, além de mim, Fernanda Beigel, Gilberto Hochman e Elisa Reis. Outros eventos comemorativos dos 50 anos da Revista Dados também foram realizados em 2016, com destaque para a Sessão Especial “50 anos da DADOS: revistas científicas, memórias e tendências da Ciência Política brasileira", realizada no dia 31 de agosto no bojo do 10 Encontro da Associação Brasileira de Ciência Política, com a participação de André Marenco, Cesar Guimarães e Charles Pessanha; e a Sessão Especial “50 anos da Revista Dados: trajetórias das ciências sociais e da editoração científica no Brasil”, realizada no dia 27 de outubro no $40^{\circ}$ Encontro da Associação Nacional, com a participação de Adrian Gurza Lavalle, Charles Pessanha e José Ricardo Ramalho.

4. O corpo docente do Instituto contava à época com três professores estrangeiros permanentes (Carlos Hasenbalg, da Argentina; Fernando Uricochea, da Colômbia; e Peter McDonough, dos Estados Unidos), aos quais se somaram uma série de visitantes. Este dinamismo internacional também estava presente na Revista DADOS, que nesta primeira etapa publicou artigos importantes de nomes como Torcuato di Tella, José Luis Reyna, S. Eisenstadt, Josef Barat, J. M. Morris, José Giral, Claus Offe, Adam Przeworski, entre outros. Autores brasileiros, como Gláucio Soares, que atuavam no exterior também colaboraram com a revista, tanto escrevendo artigos como contribuindo para sua circulação internacional.

5. O nome de Olga Lopes da Cruz pode destoar dos demais, todos eles docentes, pesquisadores e fundadores do Instituto. Trata-se, contudo, de um caso interessante. Formada em biblioteconomia, Olga foi a responsável editorial pela já mencionada Revista América Latina, editada pelo CLAPCS. Tendo em vista sua experiência em publicações e a crise do centro no início dos anos 1970, acabou colaborando temporalmente com a DADOS.

6. Este número da revista conta com um artigo de Victor Nunes Leal, preparado originalmente como conferência de abertura dos cursos de doutorado do antigo Iuperj, no dia 10 de março de 1980, além de um texto de apresentação e homenagem assinado por José Murilo de Carvalho.

7. Analiso de forma detalhada o cenário contemporâneo e alguns dos principais desafios para os periódicos de ciências sociais no Brasil em: BRINGEL, Breno (2015), "Desafios para os periódicos de ciências sociais no Brasil: cenários, atores e políticas", Revista Pensata, Unifesp, vol. 4, no 2, pp. 53-64. 


\section{A Editoria da revista DADOS agradece a todos aqueles que colaboraram de diferentes maneiras ao longo dos seus 50 anos de existência.}

Fundador

Candido Mendes

Editores(as)

Amaury de Souza

Bolívar Lamounier

Breno Bringel

Cesar Guimarães

Charles Pessanha

Jairo Nicolau

Olga Lopes da Cruz

Simon Schwartzman

Wanderley Guilherme dos Santos

Editores(as)-Assistentes

Glória Solberg

José Batista

Marcus Figueiredo

Paulo Fernando Dias Vianna

Ricardo Hernani Pires

Editores(as) Associados(as)

Alexandre Barros

Carlos Hasenbalg

Cesar Guimarães

Elisa Reis

Luiz Antonio Machado da Silva

Luiz Eduardo Soares

Renato Boschi

Conselho de Redação

Argelina Cheibub Figueiredo

Breno Bringel

Carlos R. S. Milani

Celi Scalon
Charles Pessanha

Diana Nogueira de Oliveira Lima

Fabiano Santos

Frédéric Vandenberghe

Jairo Nicolau

João Feres Júnior

José Eisenberg

José Maurício Domingues

Luiz Werneck Vianna

Marcelo Jasmin

Marcus Figueiredo

Maria Regina Soares de Lima

Renato Lessa

Ricardo Benzaquen de Araújo

Wanderley Guilherme dos Santos

Conselho Consultivo

Amaury de Souza

Antonio Octávio Cintra

Aspásia Camargo

Bolívar Lamounier

Carlos Estevam Martins

Celso Lafer

Eduardo Diatay B. de Menezes

Fábio Wanderley Reis

Fernando Henrique Cardoso

Francisco Weffort

Guillermo O'Donnell

Hélgio Trindade

Luiz Gonzaga de Souza Lima

Maria do Carmo Campello de

Souza

Mario Brockmann Machado

Otávio Guilherme Velho 
Roberto DaMatta

Roque de Barros Laraia

Ruth Cardoso

Silvio Marcelo Maranhão

Vilmar Faria

Conselho Editorial

Alexandre Barros

Amaury de Souza

Ana María Mustapic

Antonio Octávio Cintra

Antônio Sérgio Guimarães

Aspásia Camargo

Bolívar Lamounier

Candido Mendes

Carlos Hasenbalg

Carlos Estevam Martins

Celso Lafer

Cesar Guimarães

Charles Pessanha

Edmond Préteceille

Edmundo Campos Coelho

Eduardo Diatay B. de Menezes

Eli Diniz

Elisa Reis

Elísio Macamo

Enrique de la Garza Toledo

Fábio Wanderley Reis

Fernando Henrique Cardoso

Fernando Limongi

Fernando Uricoechea

Francisco Weffort

Guillermo O'Donnell

Hélgio Trindade

Ilse Scherer-Warren

José Murilo de Carvalho

Leonardo Avritzer

Licia Valladares

Luiz Antonio Machado da Silva

Luiz Carlos Bresser-Pereira

Luiz Eduardo Soares
Luiz Werneck Vianna

Maria Alice Rezende de Carvalho

Maria do Carmo Campello de

Souza

Maria Regina Soares de Lima

Mariana Llanos

Mario Brockmann Machado

Neuma Aguiar

Olavo Brasil de Lima Júnior

Otávio Guilherme Velho

Peter Wagner

Philipe Schmitter

Renato Boschi

Renato Ortiz

Ricardo Benzaquen de Araújo

Roberto DaMatta

Roque de Barros Laraia

Ruth Cardoso

Sérgio Abranches

Simon Schwartzman

Timothy Power

Vilmar Faria

Wanderley Guilherme dos Santos

Secretários(as)

Alcione José Marques

Antonio Tallon y Castilla

Beth Cobra

Claudia Boccia

Flora Abreu Henrique da Costa

Maria Alice Ramos

Patrícia Campos de Sousa

Sonia Fonseca de Oliveira

Secretaria de Redação

Ana Carolina dos Santos

Nascimento

Beth Cobra

Elisabeth Lissovsky

Márcia Rangel Candido

Márcia Rinaldi de Mattos 
Mônica Farias

Patrícia Campos de Sousa

Sabrina Primo

Tema Pechman

Projeto Gráfico

Aloysio

Carlos David

Antoninho de Paula

Antonio Seara

Emerson Genan

Rogério Duarte

Sérgio Elias

Revisão Editorial

Adriana Santos

Ana Valéria Martins Lessa

André Villalobos

Andréa Ribeiro

Anne Marie Millon Oliveira

Beth Cobra

Camila Dias da Cruz

Christopher Peterson

Cristiane Duarte Daltro Santos
David Yann Chaigne

Diane Rose Grosklaus

Duda Costa

Elisabeth Lissovsky

Estela Abreu

Geórgea Malato Franco

Gilles Pierre Mayeur

Helena Gomes Freire

Lisa Stuart

Liv Rebecca Sovik

Luna de Oliveira Sassara

Marcelle Maldonado

Márcia Rinaldi de Mattos

Marina Bezerra

Mônica Farias

Patrícia Campos de Sousa

Paulo Garchet

Renata Oliveira Rufino

Sabrina Primo

Stéphane Latarjet

Thiago Gomide Nasser

Vera Feitosa

Vera Pereira 